https://doi.org/10.5800/GT-2017-8-3-0274

\title{
GeOdynamics of THE KaZAKHSTAN OROCline, CEnTral ASIA
}

\section{Pengfei Li1, 2, Min Sun², Gideon Rosenbaum³, Chao Yuan', Inna Safonova ${ }^{4}$, Keda Caí, Yingde Jiang1, Yunying Zhang1}

${ }^{1}$ State Key Laboratory of Isotope Geochemistry, Guangzhou Institute of Geochemistry, Chinese Academy of Sciences, Guangzhou 510640, China

2 Department of Earth Sciences, The University of Hong Kong, Pokfulam Road, Hong Kong, China

${ }^{3}$ School of Earth Sciences, The University of Queensland, Brisbane 4072, Queensland, Australia

${ }^{4}$ V.S. Sobolev Institute of Geology and Mineralogy, Siberian Branch of RAS, Novosibirsk, Russia

${ }^{5}$ Novosibirsk State University, Novosibirsk, Russia

${ }^{6}$ Xinjiang Research Center for Mineral Resources, Xinjiang Institute of Ecology and Geography, Chinese Academy of Sciences, Urumqi 830011, China

For citation: Li P., Sun M., Rosenbaum G., Yuan C., Safonova I., Cai K., Jiang Y., Zhang Y., 2017. Geodynamics of the Kazakhstan orocline, Central Asia. Geodynamics \& Tectonophysics 8 (3), 505-506. doi:10.5800/GT-2017-8-3-0274.

Curved mountain belts, commonly referred as to oroclines that result from bending of quasi-linear orogenic belts, have fascinated generations of geologists. Such structures are widely recognized in modern and ancient orogens, and are fundamentally important for understanding geodynamics of convergent plate boundaries. However, how and why orogenic belts become bent has been in debate. Here we investigate the Kazakhstan Orocline in the Central Asian Orogenic Belt with an aim at understanding the geodynamics of oroclinal bending in accretionary orogens. The Kazakhstan orocline is defined by a series of U-shaped arc systems, and paleomagnetic studies have shown that the arc systems were quasi-linear prior to the Late Devonian.
The formation of the curved arc systems was previously attributed to bucking of originally linear orogenic belts in response to the convergence of the Siberian and Tarim cratons. Such a model, however, is not supported by geological observations that show a latest Carboniferous collision of the Siberian Craton with the northern limb of the Kazakhstan Orocline, which was post to the major phase of oroclinal bending in the Late Devonian to Early Carboniferous as constrained by paleomagnetic data. Alternatively, we suggest that major phase of oroclinal bending was likely due to alongstrike variation in the rate of rollback of the subducted Junggar oceanic plate, which was further tightened during the Late Carboniferous to Permian amalgama- 
tion of Siberian, Tarim and Baltic cratons. This new geodynamic model explains the occurrence of rift basins, the spatial migration of magmatic arc, and the development of large-scale strike-slip fault systems during oroclinal bending.

Acknowledgements. This study was financially supported by a Major Basic Research Project of the Ministry of Science and Technology of China (Grant: 2014CB448000 and 2014CB440801), Hong Kong Research Grant Council (HKU704712P, HKU704013P and HKU17303415), National Science Foundation of China (41273048), HKU seed funding (201111159137 and 201411159173), and Interna- tional Partnership Program of Chinese Academy of Sciences (132744KYSB20160005). This work also contributes to the Talent Award to Pengfei Li from the Chinese Government under the Thousand Youth Talents Plan, 100 Talents Program of the Chinese Academy of Sciences to Yingde Jiang, the Joint Laboratory of Chemical Geodynamics between HKU and CAS (Guangzhou Institute of Geochemistry), IGCP 592 and PROCORE France/Hong Kong Joint Research Scheme. Inna Safonova was supported by the Ministry of Education and Science of the Russian Federation (project no. 14.Y26.31.0018). 